\title{
A INSUFICIÊNCIA RENAL CRÔNICA E SUAS INTERFERÊNCIAS NO ATENDIMENTO ODONTOLÓGICO - REVISÃO DE LITERATURA
}

\section{THE CHRONIC RENAL FAILURE AND ITS INTERFERENCE IN DENTAL CARE - REVIEW OF LITERATURE}

\author{
Nayara Heloíza Medeiros* \\ Raissa Resende Alves Neves** \\ Júnia Noronha Carvalhais Amorim*** \\ Santuza Maria Souza de Mendonça****
}

\section{RESUMO}

\begin{abstract}
A insuficiência renal crônica (IRC) é uma patologia causada por alteração estrutural renal bilateral, progressiva e irreversível que ocasiona redução da capacidade de filtração glomerular. Os rins exercem funções essenciais na regulação do equilíbrio plasmático ácido-base e hidroelétrico, na síntese da eritropoetina, hidroxicolecalciferol e renina e na excreção de compostos nitrogenados, catabólitos e fármacos. A redução ou perda da função renal ocasiona complicações que devem ser consideradas no atendimento odontológico. Dentre elas estão hemorragias, maior susceptibilidade a infecções e intolerância ou sinergismo de medicamentos. Como manifestações bucais, são frequentes a xerostomia, halitose, estomatite urêmica, lesões ósseas e maior formação de tártaro. O presente artigo tem como objetivo realizar uma revisão de literatura a respeito da IRC, discutindo suas implicações e protocolos clínicos necessários para um tratamento odontológico seguro e eficaz.
\end{abstract}

DESCRITORES: Insuficiência renal crônica • Odontologia.

\section{ABSTRACT}

Chronic renal failure (CRF) is a disease caused by structural bilateral renal change, progressive and irreversible that causes reduced ability of glomerular filtration. The kidneys perform essential functions in the regulation of plasma equilibrium acid-base and hydropower; synthesis of erythropoietin hidroxicolecalciferol and renin; excretion of nitrogenous compounds, catabolites and drugs. The reduction or loss of renal function causes complications that must be considered in dental care. Among them are hemorrhage, increased susceptibility to infections and intolerance/synergism to medicines. As oral manifestations are frequent xerostomia, halitosis, uremic stomatitis, bone lesions and greater formation of tartar. The present article aims to review the literature regarding the CRF, discussing its implications and clinical protocols needed for a safe and effective dental treatment.

DESCRIPTORS: Renal insufficiency, chronic • Dentistry.

\footnotetext{
* Acadêmica do Curso de Odontologia do Centro Universitário Newton Paiva/BH-MG, nayara.h@hotmail.com

** Acadêmica do Curso de Odontologia do Centro Universitário Newton Paiva/BH-MG, raissaran@outlook.com

*** Professora Titular do Curso de Odontologia do Centro Universitário Newton Paiva; Mestre e Doutora em Patologia pela FO/UFMG, juni@morim.com.br

**** Professora Adjunta do Curso de Odontologia do Centro Universitário Newton Paiva/BH-MG; Mestre em Odontologia, área de concentração Clínica Odontológica FO/UFMG, santuzam@yahoo.com.br
} 


\section{INTRODUÇÃO}

A Insuficiência Renal Crônica (IRC) pode ser definida como uma síndrome complexa que se caracteriza pela lenta, progressiva e irreversível destruição dos néfrons ${ }^{1,2,3}$. A redução da capacidade de filtração glomerular causa uremia, caracterizada pelo acúmulo no sangue de substâncias que deveriam ser filtradas e excretadas pelos rins, com o consequente comprometimento desse órgão. Por serem unidades muito especializadas, os néfrons não apresentam capacidade regenerativa. No entanto, o rim tenta compensar essa destruição com a hipertrofia dos néfrons remanescentes ${ }^{4}$. A função renal normal é mantida até aproximadamente metade dos néfrons serem destruídos, mas alguns autores afirmam que o rim pode compensar até $75 \%$ dos néfrons perdidos $1,5,6,7$. A partir desse ponto, os néfrons perdem sua capacidade compensatória e iniciam-se as manifestações clínicas da IRC ${ }^{1,5,7}$. O rim normal participa de inúmeras funções, incluindo a regulação plasmática do equilíbrio ácido-base e hidroeletrolítico; síntese e metabolização de eritropoeitina, hidroxicolecalciferol, renina, hormônios e prostaglandina; além da excreção de compostos nitrogenados, catabolíticos e grande parte dos fármacos $5,7,8,9,10$.

No Brasil, há aproximadamente 100.500 pacientes em hemodiálise ${ }^{11}$. Portadores de IRC sob hemodiálise ou trans- plantados possuem estado clínico delicado e necessitam de atenção especial. Durante o tratamento odontológico desses pacientes, deve-se atentar para possíveis problemas como hemorragia, decorrente de anomalias funcionais plaquetárias; hipertensão arterial; anemia; intolerância/sinergismo a drogas; maior susceptibilidade à infecção e outras alterações sistêmicas ou estomatognáticas associadas à própria patologia e ao seu tratamento ${ }^{1,8,9,10}$. O aumento da sobrevida dos pacientes com IRC repercutiu na maior procura destes por tratamento odontológico, exigindo que os cirurgiões-dentistas compreendam melhor essa patologia e suas implicações ${ }^{1,}$ 6, 12, 13. Este artigo tem como objetivo realizar uma revisão de literatura a respeito da IRC, discutindo suas implicações e protocolos clínicos necessários para um tratamento odontológico seguro e eficaz.

\section{REVISÃO DA LITERATURA}

\subsection{Etiopatogenia da IRC}

As etiologias mais comuns da IRC são nefroesclerose secundária à hipertensão de longa duração, nefropatia diabética, pielonefrite, glomerulonefrite, doença renal policística, nefrite intersticial, glomerulosclerose diabética, doenças autoimunes, infecções urogenitais recorrentes, intoxicação renal causada por abuso de analgésicos e antibióticos, bem como qualquer outro processo patológico que

TABELA 1: Alterações laboratoriais na IRC

\begin{tabular}{lll}
\hline Exames Laboratoriais & Níveis Sem Alterações & $\begin{array}{l}\text { Insuficiência Renal Sintomática } \\
\text { Cleareance de Creatinina }\end{array}$ \\
\hline $\begin{array}{l}85-125 \mathrm{~mL} / \mathrm{min} . \\
(\text { Feminino) } \\
97-140 \mathrm{~mL} / \mathrm{min} . \text { (Masculino) }\end{array}$ & $\begin{array}{l}\text { (insuficiência renal moderada) } \\
<10 \mathrm{~mL} / \mathrm{min} . \\
\text { (insuficiência renal severa) } \\
\text { Creatinina Sérica }\end{array}$ & $>5 \mathrm{mg} / \mathrm{dL}$ \\
BUN & $0,6-1,20 \mathrm{mg} / \mathrm{dL}$ & $>50 \mathrm{mg} / \mathrm{dL}$ \\
Cálcio Sérico & $8-18 \mathrm{mg} / \mathrm{dL}$ & Diminuído \\
Fosfato Sérico & $8,5-10,5 \mathrm{mg} / \mathrm{dL}$ & Elevado \\
Potássio Sérico & $2,5-4,5 \mathrm{mg} / \mathrm{dL}$ & Elevado \\
\hline \hline
\end{tabular}

FONTE - ROSSI \& GLICK, 1996, p.212.

MEDEIROS NH NEVES RRA AMORIM JNC MENDONÇA SMS

A INSUFICI ÊNCIA RENAL CROONICA E SUAS INTERFERÊNCIAS NO ATENDIMENTO ODONTOLÓGICO - REVISÃO DE LITERATURA
REV, ODONTOL,

UNIV, CID, SÃO PAULO

$2014 ; 26(3): 232-$ 42, SET-DEZ 
MEDEIROS NH

NEVES RRA

AMORIM JNC

MENDONÇA SMS

A INSUFICIÊN-

CIA RENAL

CRONNICA E SUAS

INTERFER ENCIAS

NO ATENDIMENTO

ODONTOLÓGICO

- REVISÃO DE

LITERATURA

234

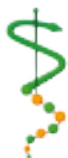

REV, ODONTOL.

UNIV. CID, SÃO

PAULO

$2014 ; 26(3): 232$

42, SET-DEZ
I SSN 1983-5183

leve a desordens renovasculares e/ou a necrose córtico-tubular renal1,5,7,8,14. O diabetes mellitus e hipertensão arterial são as doenças mais frequentemente responsáveis pela maioria dos casos da IRC. É importante que o cirurgião-dentista verifique a presença de qualquer uma dessas patologias, já que também influenciam na conduta odontológica ${ }^{1}$.

\subsection{Aspectos clínicos e diagnóstico da IRC}

A IRC é identificada por um conjunto de sinais e sintomas clínicos e pela avaliação laboratorial. A função renal é normalmente avaliada pela determinação do Nitrogênio Ureico do Sangue ${ }^{15}$ e da Creatinina, além da mensuração do débito urinário diário ${ }^{1,8,15}$. O nível elevado de ureia no sangue é patognomônico da IRC, sendo que seu diagnóstico funcional é caracterizado pela redução progressiva da taxa de filtração glomerular ${ }^{14}$. O quadro de anúria ou oligúria pode ser fator contribuinte para seu diagnóstico. A Tabela 1 mostra os indicadores laboratoriais mais comuns na avaliação da IRC ${ }^{7}$.

Os rins são capazes de compensar a diminuição da função por certo período, mantendo normais os níveis de creatinina até que ocorra a destruição de $50 \%$ da massa renal. Apesar da IRC ser assintomática em sua fase inicial, exames laboratoriais já podem identificar alterações como a homocisteinemia. Com a progressão da doença, as funções excretória, endócrina e metabólica também sofrem alterações e o indivíduo começa a apresentar anorexia, fadiga, prostração e fraqueza. O agravamento da doença pode provocar anasarca, ascite, prurido, náusea, vômito, anemia, oligúria, anúria, hipertensão arterial, letargia, insuficiência respiratória secundária à cardiopatia ou à sobrecarga de líquido, hipertensão secundária e pericardite. Por fim, o indivíduo pode evoluir para quadros clínicos de convulsões até o coma $^{1,5,7,16}$.

Ao exame clínico, os portadores da IRC apresentam hipertensão, pele pálida e amarelada, com possíveis áreas escoriadas e mucosa bucal pálida. A retenção de líquidos é evidente. Os indivíduos também podem manifestar Insuficiência Car- díaca Congestiva (ICC), com hipertrofia cardíaca e terceira bulha ${ }^{7,8}$.

Os exames laboratoriais e as anormalidades metabólicas são:

- Coagulograma - Tempo de sangramento prolongado, resultante da inibição da adesão das plaquetas pelas toxinas urêmicas $5,8,14,17$.

- Hemograma - anemia normocrômica e normocítica resultante da falta de produção de eritropoetina ${ }^{17}$.

- Eletrólitos - Hipercalemia; acidose secundária à retenção de potássio e ácidos; taxa de fosfato sérico elevada, devido à retenção de fosfato; taxa de cálcio sérico diminuída, devido ao prejuízo da síntese de vitamina D; BUN e creatinina sérica elevados8,14.

2.3 Evolução e abordagem terapêutica da IRC

A evolução clínica da IRC depende das complicações a ela associadas. Nos indivíduos com hipertensão e nefropatia diabética a evolução é rápida, enquanto aqueles com doença renal policística têm evolução lenta. O aumento progressivo da azotenia demanda tratamento dialítico ou transplante ${ }^{1,5,8}$.

A abordagem terapêutica da IRC é realizada em três etapas. Inicialmente o tratamento médico associado ao controle da dieta é eficaz para manutenção da homeostase. Com o avanço da IRC, há necessidade da filtração sanguínea artificial (diálise peritoneal ou hemodiálise). A fase final é o transplante renal ${ }^{18}$.

\subsubsection{O Tratamento conservador}

Baseia-se no controle rigoroso da ingestão de sódio, potássio, água e proteínas. O uso de diuréticos é fundamental ${ }^{1,2,5,8,14,19}$. A anemia causada pela IRC é bem tolerada e nenhum tratamento adicional é necessário, a não ser que o indivíduo apresente sintomas severos. Nesses casos, pode ser usada eritropoetina, terapia com ferro ou transfusão sanguínea ${ }^{1,2,5}$. Deve-se evitar o uso de qualquer medicamento nefrotóxico ou metabolizado nos rins ${ }^{19}$.

\subsubsection{A Diálise}

O objetivo da diálise é manter as concentrações ideais de fluidos/eletrólitos e promover a excreção. Esse procedimento desempenha a função metabólica do rim, mas não corrige anormalidades endócri- 
nas, doenças ósseas, neuropatias e alterações associadas à IRC. O sangue é filtrado para retirada de água e metabólitos em excesso. Na diálise peritoneal, a membrana peritoneal, rica em vasos sanguíneos, atua como filtro. Já na hemodiálise, o dialisador, presente no interior dos aparelhos, realiza a filtragem. De maneira geral, os pacientes iniciam seu tratamento com a diálise peritoneal e podem progredir para hemodiálise, se a função renal continuar a diminuir ${ }^{1,2,5,7,8,20}$.

A hemodiálise pode ser realizada de duas a três vezes por semana em dias alternados e as sessões duram em média quatro horas. É um momento tenso e angustiante para o paciente, por isso seu impacto psicológico deve ser considerado ${ }^{7,14}$. O membro no qual está o acesso vascular da hemodiálise nunca deve ser utilizado para aplicação de medicamentos ou aferição da pressão arterial. O paciente sob hemodiálise apresenta alto risco para endocardite infecciosa e infecções intravasculares, visto que o acesso vascular aumenta o risco de formação de trombos infecciosos, contribuindo para ocorrência de bacteremia persistente ou êmbolos sépticos. Assim, a antibioticoterapia é sempre indicada em procedimentos invasivos. $\mathrm{O}$ uso da vancomicina endovenosa durante o procedimento de diálise é preconizado, não havendo necessidade de complementação em doses posteriores, pois a vancomicina tem ação por 4 a 7 dias nos nefropatas $^{1,2,5,6,7,12}$.

A diálise inadequada pode provocar estado urêmico, acompanhado de náuseas, vômitos, anorexia e consequente prejuízo ao consumo alimentar ${ }^{3}$. Dependendo do parâmetro utilizado, a prevalência de desnutrição entre os indivíduos sob diálise varia de 10 a $54 \%^{21}$. A IRC pode levar à deficiência de zinco, gerando também quadro de anorexia, aumento nos níveis séricos de noradrenalina, cicatrização lenta, atraso na maturação óssea, disfunções imunológicas e hipogeusia ${ }^{22}$.

\subsubsection{O Transplante}

A fase terminal da insuficiência renal crônica ocorre quando a função renal do indivíduo não é mais capaz de manter a vida ${ }^{5}$. O transplante ainda é a melhor técnica de tratamento nesse estágio da doença. O maior problema apresentado por pacientes transplantados é a deficiência imunológica causada por drogas imunossupressoras, utilizadas para prevenir a rejeição do rim transplantado. Os fármacos mais utilizados são tacrolimus, ciclosporina, prednisona, sirolimus, azatiopia, micofenolato mofetil ou micofenolato de sódio, globulina antimocítica: ATG, OKT3 23.

\subsection{Manifestações bucais da IRC}

Os pacientes com IRC apresentam halitose, estomatite urêmica, gengivite, fluxo salivar diminuído, xerostomia e parotidite. Um dos primeiros sintomas bucais é gosto ruim na boca e halitose ao acordar, ambos causados pela alta concentração de uréia na saliva e seu metabolismo em amônia ${ }^{5,12,15,24,25,26}$. A xerostomia no portador de IRC tem-se o envolvimento direto das glândulas salivares, desidratação e respiração bucal1 ${ }^{1,5,24}$. Um estudo conduzido em 1998 não identificou diferença estatisticamente significante no fluxo salivar total estimulado de pacientes portadores de IRC e controles ${ }^{14}$.

Sessenta por cento dos pacientes transplantados devido à IRC apresentam pelo menos uma lesão bucal. Dentre as alterações bucais mais encontradas estão infecção herpética, candidose, papiloma, leucoplasia pilosa, língua saburrosa, carcinoma escamocelular de lábio e linfoma não Hodgkin ${ }^{5,13,27}$. O achado bucal mais frequente é palidez da mucosa, sinal da anemia $^{1,12}$. Outros autores destacam, porém, que as alterações bucais mais frequentes em transplantados renais são mucosites, hipossalivação, infecções por vírus da família Herpes e Citomegalovírus $^{25}$. A estomatite urêmica, relacionada ao aumento do BUN, é caracterizada por mucosa avermelhada ou ulcerada recoberta por espessa pseudomembrana que desaparece com a normalização do BUN. Sua etiologia ainda é desconhecida, mas existem suspeitas de que seja uma reação da mucosa à ureia salivar. As lesões são dolorosas e aparecem mais frequentemente na face ventral da língua e soalho bucal ${ }^{1,8,24,25}$.

Alterações ósseas como desmineralização, redução progressiva de trabeculagem, perda total ou parcial da lâmina
MEDEIROS NH NEVES RRA AMORIM JNC MENDONÇA SMS

A INSUFICI ÊNCIA RENAL CRONICA E SUAS INTERFERÊNCIAS NO ATENDIMENTO ODONTOLÓGICO - REVISÃO DE LITERATURA

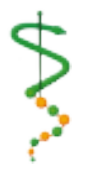

REV, ODONTOL.

UNIV, CID, SÃo PAULO

2014; 26(3): 232 42, SET-DEZ 
MEDEIROS NH

NEVES RRA

AMORIM JNC

MENDONÇA SMS

A INSUFICI ÊN-

CIA RENAL

CRONNICA E SUAS

INTERFER ENCIAS

NO ATENDIMENTO

ODONTOLÓGICO

- REVISÃO DE

LITERATURA

236

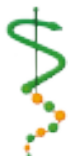

REV, ODONTOL.

UNIV. CID, SÃO

PAULO

$2014 ; 26(3): 232$

42, SET-DEZ dura, lesão de células gigantes e calcificações metastáticas também são observadas com frequênciaa ${ }^{1,5,10,18,28}$. Tais manifestações são mais comuns na região posterior da mandíbula, podendo ser causas de fraturas espontâneas e calcificações de tecidos moles. Após exodontia, é comum acontecer remodelação anormal do osso, caracterizada pela ausência de reabsorção da lâmina dura e deposição de osso esclerótico ${ }^{5}$. Dentre os pacientes com IRC, 5\% a $25 \%$ deles desenvolvem hiperparatireoidismo secundário. Em relação aos que realizam diálise, essa porcentagem aumenta para 50\%. O hiperparatireoidismo secundário provoca hiperplasia da glândula paratireoide, aumentando a síntese e secreção do paratormônio (PTH). Tal fato gera fatores contribuintes às alterações ósseas como hipocalcemia, hiperfosfatemia, deficiência de calcitrol e da resistência óssea, dores osteomusculares, calcifilaxia, fraturas, deformidades ósseas e osteoclastomas $^{29}$. Os indivíduos com IRC possuem ligeira perda da crista óssea e aumento da distância entre crista alveolar e união amelocementária ${ }^{10}$.

A literatura cita ainda, como alterações da IRC, mobilidade dentária, diminuição da câmara pulpar devido a calcificações e a hipoplasia de esmalte. A hipoplasia de esmalte ocorre quando a uremia está presente no período de formação dos dentes e pigmentos sanguíneos, de coloração amarronzada, ficam retidos no esmalte dentário. Alguns portadores de IRC apresentam maior risco de erosão dentária devido à regurgitação, consequência da náusea, muito comum no processo de diálise ${ }^{1,5}$. Em crianças com IRC é comum atrasos na cronologia de erupção dos dentes permanentes ou ordem de erupção alterada, além de hipoplasia de esmalte e pigmentações dentárias ${ }^{1,10,25}$.

Muitos estudos recentes têm demonstrado associação entre doenças renais crônicas e doenças do periodonto. A IRC pode predispor e/ou agravar a doença periodontal (DP), da mesma forma que a DP pode ser fator de comorbidade e fonte oculta de inflamação, causando ou favorecendo o dano renal ${ }^{30,31}$. Apesar do possível aumento da incidência e severidade da DP em pacientes com IRC, a DP pode ser controlada através da terapia periodontal, propiciando melhoria da saúde bucal e efeito positivo sobre a morbidade e mortalidade desses pacientes. O tratamento da DP pode contribuir para diminuição dos marcadores sistêmicos de inflamação, melhora da glicemia e controle metabólico, restaurando parcialmente a disfunção endotelial com consequente melhora da condição sistêmica e qualidade de vida dos pacientes renais crônicos. O diagnóstico precoce, tratamento e controle da DP, associados à avaliação periódica da saúde bucal, desde os estágios iniciais da doença renal crônica, devem ser intensificados como fatores de prevenção de comorbidades. A integração do cirurgião-dentista às clínicas de diálise e equipe multiprofissional certamente terá impacto positivo no estado de saúde bucal e sistêmica dos pacientes renais crônicos ${ }^{31}$.

Em 2011 foi realizado estudo transversal com indivíduos em hemodiálise. Entre os pacientes, 52,9\% apresentaram perda de inserção clínica menor que $2 \mathrm{~mm}$, enquanto $47,1 \%$ tinham DP. Notou-se que a perda de inserção era maior nos pacientes idosos ${ }^{32}$.

Em estudo tipo caso-controle com portadores de IRC submetidos à hemodiálise e pacientes saudáveis, avaliou-se a microflora bacteriana e a prevalência de cárie e cálculo dental. Os resultados revelaram que pacientes com IRC têm alta predisposição à formação de cálculo, provavelmente devido à grande concentração de ureia na saliva e alteração do cálcio e fosfato séricos. A elevada concentração de ureia associada à presença aumentada de amônia na saliva é responsável pelo $\mathrm{pH}$ significativamente mais alcalino no grupo-caso do que no do grupo-controle. Isso contribui para que a placa bacteriana se torne também mais alcalina, podendo influenciar sua microbiota e atividade metabólica. Observou-se ainda que pacientes portadores de IRC apresentavam quantidade de microrganismos cariogênicos semelhante aos pacientes saudáveis ${ }^{14}$. Outro estudo concluiu que pacientes com IRC possuem maior acúmulo de cálculo dentário e placa, sendo a arcada inferior a mais afetada ${ }^{33}$.

Em 2012 foram avaliados 75 pacientes 
em hemodiálise. Destes, 37\% apresentaram boa higiene bucal e $63 \%$ higiene bucal precária. O acometimento periodontal foi evidente, pois $24 \%$ dos pacientes apresentaram gengivite e $75 \%$ periodontite. Os autores sugeriram que inter-relação entre nefrologistas e dentistas é necessária para mudança desse quadro ${ }^{26}$. Apesar dos pacientes portadores de IRC possuírem dieta rica em carboidratos, devido à restrição de proteínas, eles apresentam baixa prevalência de cárie. Esse fato decorre da inibição da formação da placa bacteriana e do crescimento de bactérias cariogênicas devido aos altos índices de ureia na saliva ${ }^{1}$. A elevada concentração de amônia na saliva que ocorre nos estágios finais da IRC favorece o desenvolvimento de estomatite com características clínicas semelhantes àquelas da Gengivite Ulcerativa Necrosante ${ }^{34}$.

É necessário conscientizar o paciente portador de IRC das possíveis consequências das doenças bucais em sua saúde geral, bem como elaborar estratégias para o seu atendimento odontológico ${ }^{14,15}$. É importante a adoção de medidas preventivas desde o primeiro contato do cirurgião-dentista com o paciente, evitando-se o aparecimento de focos infecciosos e perda prematura de dentes ${ }^{10}$. As manifestações bucais associadas à IRC são secundárias às manifestações sistêmicas e não são específicas para diagnosticar a doença renal crônica².

2.5 Diagnóstico e planejamento odontológicos no indivíduo com IRC

O tratamento odontológico de portadores da IRC sob hemodiálise e comumente candidatos ao transplante renal não consiste apenas das resoluções de necessidades odontológicas preexistentes, mas também do controle das infecções derivadas da IRC na cavidade bucal e toda a região maxilofacial ${ }^{24}$. O tipo de tratamento odontológico depende do estágio de destruição renal e controle da doença. Em indivíduos bem controlados, os tratamentos de rotina como polimento coronário, raspagens e restaurações podem ser realizados no próprio consultório. Caso a doença não esteja sob controle e o indivíduo apresente estágios avançados de destruição renal, recomenda-se atendimento em ambiente hospitalar 5 .

Os portadores de IRC precisam de cuidados especiais e apoio humano, pois apresentam situação psicológica delicada e vivem sob condições estritamente controladas. Tais pacientes são incapazes de tolerar variações significativas na dieta, fluidos e atividades diárias. Escolhendo os momentos corretos, é possível realizar todo o tratamento odontológico sem interrupção da diálise. O tratamento odontológico não deve comprometer a saúde geral do paciente, nem interferir no tratamento médico ou piorar a condição física do paciente ${ }^{6}$. É importante que o cirurgião-dentista entre em contato com o médico responsável para se informar quanto à estabilidade e estágio da doença a fim de planejar o tratamento. O tratamento odontológico de pacientes descompensados deve ser adiado até que estejam estabilizados ${ }^{5}$.

A pressão arterial do paciente com IRC deve ser rigorosamente monitorada antes e durante todo o tratamento odontológico. Ele deverá apresentar exames recentes para controle do tempo de sangramento, contagem de plaquetas, hematócrito, nível de hemoglobina e tempo de protrombina $^{5}$. Para procedimentos odontológicos invasivos, a profilaxia antibiótica deverá ser realizada conforme preconizada pela American Heart Association. Em casos de infecções pós-operatórias, estas devem ser tratadas agressivamente ${ }^{1,2,5,12,35}$. É necessário cautela no tratamento odontológico de portadores da IRC, visto que apresentam, com frequência, anemia normocrômica ou normocítica. Tais anemias são de difícil tratamento, podendo aumentar o risco de hemorragias em procedimentos cirúrgicos $^{6}$. A predisposição à hemorragia é um problema constante nos pacientes sob hemodiálise devido à fragilidade capilar, diminuição da adesão e agregação plaquetária e tempos de sangramento e coagulação prolongados. Além disso, esses pacientes ainda recebem medicamentos anticoagulantes, como a heparina, para evitar formação de coágulos durante as sessões de hemodiálise. Por isso, o tratamento odontológico deve ser realizado no primeiro dia após a diálise, quando a ação anticoagulante é mínima e os benefícios
MEDEIROS NH

NEVES RRA

AMORIM JNC

MENDONÇA SMS

A INSUFICI ÊN-

CIA RENAL

CRONICA E SUAS

INTERFERÊNCIAS

NO ATENDIMENTO

ODONTOLÓGICO

- REVISÃO DE

LITERATURA

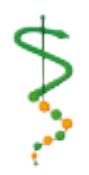

REV, ODONTOL.

UNIV. CID. SÃo

PAULO

2014; 26(3): 232 -

42, SET-DEZ 
MEDEIROS NH

NEVES RRA

AMORIM JNC

MENDONÇA SMS

A INSUFICIÊN-

CIA RENAL

CRONNICA E SUAS

INTERFER ENCIAS

NO ATENDIMENTO

ODONTOLÓGICO

- REVISÃO DE

LITERATURA

$238 \ldots$

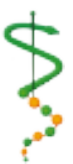

REV, ODONTOL.

UNIV, CID, SÃO

PAULO

$2014 ; 26(3): 232$

42, SET-DEZ da diálise estão presentes ${ }^{1}$. Os procedimentos cirúrgicos devem ser realizados no intervalo entre uma sessão de diálise e outra, quando o sangue está livre de heparina e há tempo suficiente para que ocorra estabilização do coágulo e início do processo de cicatrização. O cirurgião-dentista deve utilizar medidas de hemostasia local (trombina tópica, colágeno microfibrilar e sutura) para controle do sangramento, além de executar técnica cirúrgica meticulosa ${ }^{1,2,5,7,12,19,36}$.

Qualquer procedimento cirúrgico em pacientes com IRC possui risco significativo. Esse fato se deve à elevada prevalência de doenças clínicas coexistentes e efeitos prejudiciais das anormalidades metabólicas e eletrolíticas, que podem dificultar a cicatrização de feridas cirúrgicas e diminuir a capacidade de suportar os excessos perioperatórios ${ }^{37}$.

As infecções oportunistas são causa constante de morbidade e mortalidade em pacientes sob hemodiálise ${ }^{1,12}$. A infecção do acesso vascular é a principal sequela da hemodiálise e pode levar o paciente ao óbito; assim, procedimentos preventivos contra infecções são de extrema importância ${ }^{2}$.

Assim, a condição bucal dos pacientes com IRC candidatos a transplante renal deve estar controlada durante a hemodiálise, períodos pré-transplante e pós-transplante ${ }^{38}$. As complicações advindas de uma infecção bucal não tratada em paciente imunossuprimido podem ser severas e contribuírem para a morbidade e rejeição do órgão transplantado ${ }^{12,15}$.

A proteína C-reativa e imunoglobulinas, especialmente a IgG, são mediadores inflamatórios produzidos durante as reações bacterianas no periodonto e podem causar danos aos rins ${ }^{39}$. Da mesma forma, as bactérias catalogadas como periodontopatogênicas podem agir à distância ou atingir órgãos vitais através da corrente sanguínea. Tais microorganismos podem se instalar não só no glomérulo como nos vasos sanguíneos, acelerando a aterosclerose, principal causa das complicações cardiovasculares em pacientes renal e responsável por $60 \%$ da taxa de mortalidade em pacientes sob diálise ${ }^{30}$. Os patógenos periodontais como Porphyromonas gingivalis podem causar injúria direta do néfron, uma vez que muitos dos procedimentos odontológicos provocam bacteremia transitória e os produtos bacterianos podem atingir o endotélio renal ${ }^{40,41}$.

O planejamento integral odontológico do portador da IRC precisa incluir exodontias de dentes não passíveis de restaurações ou severo comprometimento periodontal, restauração das lesões cariosas ativas cavitadas e tratamento endodôntico dos dentes com comprometimento pulpar. Além disso, é preciso incentivar o hábito de higienizar a cavidade bucal através de orientações sobre escovação, uso do fio dental, nutrição e fluo$\operatorname{retos}^{2,5,12,19,38,42}$. É de fundamental importância a implementação de um programa preventivo/terapêutico direcionado aos pacientes com IRC, através do qual seria possível conscientizá-los sobre a importância da saúde bucal para a realização e manutenção do transplante renal ${ }^{4}$.

A indicação de bochechos com soluções antimicrobianas, como a clorexidina $(0,12 \%)$, antes do atendimento, tem mostrado bons resultados na diminuição de microrganismos patogênicos bucais em pacientes transplantados $^{5}$. O tratamento periodontal consiste em facilitar o controle de placa, adicionando aos métodos clássicos de higienização o uso de uma escova elétrica ou um irrigador pulsante com solução de peróxido de hidrogênio $2 \%{ }^{43}$.

Os pacientes transplantados fazem uso de agentes imunossupressores que mascaram os sinais iniciais das infecções bucais, dificultando seu diagnóstico precoce. Quando processos agudos se desenvolvem são mais avançados e mais severos do que em pacientes normais ${ }^{2,5,12}$. O cirurgião-dentista deve estar ciente da alta prevalência de candidose em pacientes transplantados ${ }^{19}$. Algumas formas de candidose como: pseudomembranosa $(1,9 \%)$, eritematosa $(3,8 \%)$ e atrófica $(3,8 \%)$ foram relatadas em pacientes transplantados, mostrando maior suscetibilidade desses pacientes a infecções fúngicas $^{34,44}$. Agentes antifúngicos como a nistatina são utilizados no controle de infecções localizadas ${ }^{19}$.

Os pacientes que estão sob uso de esteroides apresentam risco de ter crise aguda da adrenal durante o atendimento odontológico. A necessidade de suplementação 
da dose de esteroide deve ser discutida com o médico responsável. Mesmo com a suplementação da dose de esteroide, o dentista deve estar atento a qualquer sinal de crise da adrenal, que inclui rápido desenvolvimento de hipotensão, fraqueza, náusea, vômito, dor de cabeça e febre. Deve-se sempre ter esteroide disponível no consultório para qualquer emergência de crise da adrenal. Os corticosteroides também podem prejudicar o tratamento odontológico, visto que interferem na proliferação de fibroblastos, recapilarização, síntese de mucopolissacarídeos e mineralização da matriz óssea em formação ${ }^{2,5}$.

Para todos os pacientes transplantados, é obrigatória a antibioticoterapia em casos de procedimentos invasivos. A prescrição de medicamentos e o cuidado com drogas nefrotóxicas continua sendo importan$\mathrm{te}^{2,5,19}$.

A terapia endodôntica em pacientes transplantados com abcesso periapical só poderá ser realizada se os mesmos apresentarem boas condições de saúde e é desaconselhada, caso haja envolvimento periapical severo e potencialmente perigoso a ponto de disseminar uma infecção. Qualquer tratamento endodôntico deve ser proservado anualmente através de radiografias $^{12}$.

\subsection{Fármacos}

Como o metabolismo e excreção de muitas drogas apresentam-se alterados em indivíduos com IRC, desaconselha-se o uso de fármacos em altas dosagens; excretados pelos rins ou nefrotóxicos. Felizmente, a maior parte dos medicamentos utilizados em Odontologia são seguros para pacientes renais em doses terapêuticas, apesar de existirem algumas exceções $^{18}$. O domínio do conhecimento sobre uso de fármacos e sua toxicidade é importante para o tratamento de pacientes com IRC ${ }^{5}$. O ajuste da dose de drogas eliminadas exclusivamente pelos rins é feito de acordo com o nível de prejuízo da função renal, medicação e existência de outros problemas sistêmicos. Dois métodos são usados para ajustar o uso de medicamentos: redução da quantidade de droga com manutenção do intervalo de administração e manutenção da quantidade da droga com prolongamento do intervalo de administração ${ }^{5,12}$.

Os pacientes renais crônicos podem ser submetidos à anestesia local, desde que sejam utilizadas doses conservadoras. Anestésicos locais como lidocaína podem ser usados normalmente, visto que possuem metabolismo predominantemente hepático. A administração de cinco a seis tubetes de solução de lidocaína é bem tolerada e segura ${ }^{5,12}$. Amoxicilina, eritromicina e clindamicina podem ser utilizadas em suas doses usuais e são os antibióticos de escoIha, no entanto podem alterar o metabolismo das drogas imunossupressoras ${ }^{5,12,18}$. A tetraciclina e estreptomicina não devem ser utilizadas em pacientes com problemas renais, pois são nefrotóxicas e contribuem para acúmulo de ureia $^{18}$. O ácido acetil salicílico e o acetaminofeno podem ser utilizados em doses baixas ou moderadas por períodos curtos de tempo ${ }^{18}$. No entanto, alguns autores, contraindicam o uso do ácido acetil salicílico por sua interferência na coagulação sanguínea e potencial ulcerogênico, principalmente em pacientes que fazem uso de corticosteroide ${ }^{5,12}$. A codeína pode ser usada para controle da dor, uma vez que apresenta seu metabolismo no fígado ${ }^{18}$. Anti-inflamatórios são contraindicados e analgésicos, principalmente os morfinomiméticos, devem ser utilizados com cautela ${ }^{7}$.

\subsection{Controle odontológico periódico}

O controle odontológico periódico e o reforço de medidas preventivas devem ser realizados a cada três ou quatro meses. Um exame bucal criterioso deve ser feito em pacientes transplantados que usam ciclosporina, pois estes estão sob risco de desenvolver hiperplasia gengival medicamentosa. O controle radiográfico dos tratamentos endodônticos deve ser realizado anualmente e o paciente instruído a procurar o dentista imediatamente, caso ocorra qualquer alteração em sua cavidade bucal. A avaliação periodontal deve ser criteriosa $^{10,12}$.

\section{CONSIDERAÇÕES FINAIS}

Os pacientes portadores de IRC ou transplantados renais apresentam maior predisposição para o desenvolvimento de patologias bucais. O cirurgião-dentista deve trabalhar de forma interdisciplinar
MEDEIROS NH

NEVES RRA

AMORIM JNC

MENDONÇA SMS

A INSUFICI ÊN-

CIA RENAL

CRONNICA E SUAS

INTERFERÊNCIAS

NO ATENDIMENTO

ODONTOLÓGICO

- REVISÃO DE

LITERATURA

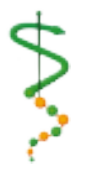

REV, ODONTOL.

UNIV, CID , SÃO

PAULO

2014; 26(3): 232 -

42, SET-DEZ 
MEDEIROS NH

NEVES RRA

AMORIM JNC

MENDONÇA SMS

A INSUFICIÊN-

CIA RENAL

CRONNICA E SUAS

INTERFERENCIAS

NO ATENDIMENTO

ODONTOLÓGICO

- REVISÃO DE

LITERATURA

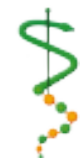

REV, ODONTOL.

UNIV, C I D , S ÃO PAULO

$2014 ; 26(3): 232-$

42, SET-DEZ
I SSN 1983-5183

visando à assistência integral do indivíduo. Durante o tratamento odontológico, esses pacientes merecem cuidados especiais, principalmente no que se refere a processos hemorrágicos, presença de focos de infecção e administração de anestésicos ou outros fármacos. Os principais objetivos do atendimento odontológico ao portador da IRC são: medida preventiva, detecção precoces de alterações bucais, viabilizando um tratamento mais conservador. O portador de IRC deve ser

\section{REFERÊNCIAS}

1. De Rossi SS, Glick M. Dental considerations for the patient with renal disease receiving hemodialysis. J Am Dent Assoc 1996 Feb;127(2):211-9.

2. Ferguson CA, Whyman RA. Dental management of people with renal disease and renal transplants. $\mathrm{N} Z$ Dent J 1998 Sep;94(417):125-30.

3. Cabral PC, Diniz AS, Arruda IKG. Avaliação nutricional de pacientes em hemodiálise. Rev Nutr 2005 18(1):29-40.

4. Dias CRS, Sá TCV, Pereira ALA, Alves em pacientes renais crônicos submetidos à hemodiálise. Rev Assoc Med Bras 2007 56(6):510-4.

5. Naylor GD, Fredericks MR. Pharmacologic considerations in the dental management of the patient with disorders Am 1996 Jul;40(3):665-83.

6. Manton SL, Midda M. Renal failure and the dental patient: a cautionary tale. $\mathrm{Br}$ Dent J 1986 Jun 7;160(11):388-90.

7. Jorge WA, Elias FM, Jorge MD, Tastaldi M, Gonçalves S. Urgências sistêmicas em consultório odontológico. In: Feller C, Gorab R. Atualização na clínica odontológica: módulos de atualização. São Paulo: Artes Médicas; 2000. p. 535-74.

8. Sonis ST, Fazio R, Fang L. Princípios e prática de Medicina oral. 2. ed. Rio de Janeiro: Guanabara Koogan; 1995. CMC. Avaliação da condição bucal of the renal system. Dent Clin North conscientizado sobre as possíveis consequências das doenças bucais e sua saúde geral. O papel do cirurgião dentista é de enfatizar que o sucesso do transplante e de qualquer outro tratamento depende diretamente do envolvimento do paciente juntamente com ele, para que se obtenha uma saúde bucal ideal. O profissional deve estar preparado adequadamente para atender tais pacientes, já que merecem e necessitam de um atendimento visando o mesmo como um todo.
9. MAFRA, D.; ABDALIA, D. S. P. \& COZZOLINO, S. M. F. Peroxidação Lipídica em pacientes com Insuficiência Renal Crônica. Rev. Nutr., Campinas, set.-dez., 1999; 12(3):205-212.

10. TOVAR, M. G.; RÍOS, R.F.; TREJO, J.G.; RUIDÍAZ, V.C.; CEPEDA, L.A.G. Altura de cresta alveolar en pacientes pediátricos con insuficiencia renal crónica. Revista Odontológica Mexicana, v.8, n.3, Cidade do México, set.2004:75-79,

11. Censo da sociedade brasileira de nefrologia. Censo de diálise SBN 2013. 2013. Disponível em: http//www.sbn. org.br/pdf/censo_2013_publico_leigo. pdf.

12. Eigner TL, Jastak JT, Bennett WM. Achieving oral health in patients with renal failure and renal transplants. J Am Dent Assoc 1986 Oct;113(4):6126.

13. Carvalho AAT, Figueira MAS, Melo SHL. Transplante renal: a influência da terapia imunosupressora na prevalência de manifestações estomatológicas Odontol clín-cient 2003 set.-dez.;2(3):165-73.

14. Fujimaki M, Rosa OPS, Torres SA. Microrganismos cariogênicos em pacientes com insuficiência renal crônica em hemodiálise. Rev Odontol Univ São Paulo 1998 apr.;12(2):149-58. 
15. Souza CRD, Libério SA, Guerra RNM, Monteiro S, Silveira ÉJD, Pereira ALA. Avaliação da condição periodontal de pacientes renais em hemodiálise. Rev Assoc Med Bras 2005 Out.;51(5):2859 .

16. Nerbass FB, Draibe SA, Cuppari L. Hiperhomocisteinemia na insuficiência renal crônica. Rev Nutr 2005 Abr.;18(2):239-49.

17. Farias JG, Carneiro GGVS, Batista BA, Barreto Neto LO, Moraes LC, Meirelles MM. Avaliação odontológico-cirúrgica do paciente renal crônico. Rev cir traumatol buco-maxilo-fac 2008 jan-mar;8(1):

18. Little JW, Falace DA. Therapeutic considerations in special patients. Dent Clin North Am 1984 Jul;28(3):455-69.

19. Naylor GD, Hall EH, Terezhalmy GT. The patient with chronic renal failure who is undergoing dialysis or renal transplantation: another consideration for antimicrobial prophylaxis. Oral Surg Oral Med Oral Pathol 1988 Jan;65(1):116-21.

20. Proctor R, Kumar N, Stein A, Moles $\mathrm{D}$, Porter S. Oral and dental aspects of chronic renal failure. J Dent Res 2005 Mar;84(3):199-208.

21. Santos NSJ, Draibe SA, Kamimura MA, Cuppari L. Albumina sérica como marcador nutricional de pacientes em hemodiálise. Rev Nutr, Campinas 2004 jul-set;17(3):339-49.

22 Mafra, D. \& Cozzolino, S. M. F. Importância do Zinco na nutrição Humana. Rev. Nutr., Campinas, jul.-set. 2004; 17(1):79-87.

23. Long D, Kosmach-Park B, Vellani S, Stein $M$, Pharm WM, James $M$, et al. Manual de trasplante de riñón: guía para el cuidado de su salud después del trasplante de riñón. 2007. Disponível em: http://www.itns.org/uploads/ Manual_del_riqsn.pdf.
24. Kho HS, Lee SW, Chung SC, Kim YK. Oral manifestations and salivary flow rate, $\mathrm{pH}$, and buffer capacity in patients with end-stage renal disease undergoing hemodialysis. Oral Surg Oral Med Oral Pathol Oral Radiol Endod 1999 Sep;88(3):316-9.

25. Tan Castañeda N, Rodríguez Calzadilla A. Correspondencia entre la formación académica del estomatólogo relacionado con pacientes especiales y la práctica estomatológica integral. Rev Cubana Estomatol 2001 38(3):181-91.

26. Bhatsange A, Patil SR. Assessment of periodontal health status in patients undergoing renal dialysis: A descriptive, cross-sectional study. J Indian Soc Periodontol 2012 Jan;16(1):37-42.

27. de la Rosa-Garcia E, Mondragon-Padilla A, Irigoyen-Camacho ME, Bustamante-Ramirez MA. Oral lesions in a group of kidney transplant patients. Med Oral Patol Oral Cir Bucal 2005 May-Jul;10(3):196-204.

28. Tomat A, Gamba CA, Mandalunis P, De Grandi MC, Somoza J, Friedman $S$, et al. Changes in bone volume and bone resorption by olpadronate treatment in an experimental model of uremic bone disease. J Musculoskelet Neuronal Interact 2005 Jun;5(2):17481.

29. Peters BSE, Jorgetti V, Martini LA. Influência do hiperparatireoidismo secundário grave no estado nutricional de pacientes com insuficiência renal crônica. Rev Nutr, Campinas 2006 fev;19(1):111-8.

30. Bayraktar G, Kurtulus I, Kazancioglu R, Bayramgurler I, Cintan S, Bural C, et al. Effect of educational level on oral health in peritoneal and hemodialysis patients. Int J Dent 2009 2009(159767.

31. Almeida DC, Pereira CS, Granjeiro JM, Machado WAS, Regina F, Tostes $V$, et al. Relação bidirecional entre doença periodontal e doença renal crônica: da progressão da doença renal crônica à terapia renal substitutiva de diálise. Rev Periodontia 2011 mar;21(1):73-9.
MEDEIROS NH NEVES RRA AMORIM JNC MENDONÇA SMS

A INSUFICIÊNCIA RENAL CRONICA E SUAS INTERFERENNCIAS NO ATENDIMENTO ODONTOLÓGICO - REVISÃO DE LITERATURA
REV, ODONTOL. UNIV, CID, SÃo PAULO 2014; 26(3): 232 42, SET-DEZ 
MEDEIROS NH

NEVES RRA

AMORIM JNC

MENDONÇA SMS

A INSUFICIÊN-

CIA RENAL

CRONNICA E SUAS

INTERFER ENCIAS

NO ATENDIMENTO

ODONTOLÓGICO

- REVISÃO DE

LITERATURA

242
ISSN 1983-5183

32. Gonçalves ÉM, Lima DLF, Albuquerque SHC, Carvalho JA, Cariri TFA, Oliveira CMC. Avaliação da perda de inserção dentária em pacientes com doença renal crônica em hemodiálise. J Bras Nefrol 2011 set;33(3):291-4.

33. Sousa FACV, Rosa LEB, Almeida JD, Cabral LAG. Mieloma múltiplo: uma breve revisão. Rev bras patol oral 2004 out-dez;3(4):176-9.

34. Oliveira CS, Artese HPC, Silva AG, Delgado A, Torres MCMB. Manifestações bucais e doença renal crônica: revisão de literatura. Periodontia 2008 18(1):14-9.

35. American Heart Association. Infective endocarditis. 2015. Disponível em: http://www.heart.org/HEARTORG/ Conditions/CongenitalHeartDefects/ ThelmpactofCongenitalHeartDefects/ Infective-Endocarditis_UCM_307108_ Article.jsp.

36. Sowell SB. Dental care for patients with renal failure and renal transplants. J Am Dent Assoc 1982 Feb;104(2):1717.

37. Pinto AVS, Miyagusko JM, Ramalho SA, Wassall T, Pereira LAV. Fatores de risco, complicações e fracassos na terapêutica com implantes osseointegrados. In: Feller C, Gorab R. Atualização na clínica odontológica: módulos de atualização. São Paulo: Artes Médicas; 2000. p. 131-216.

38. Pupo MLMGS, Parizoto GA, Gonzaga CC, Lopes KGK. Índice de risco odontológico para pacientes pré-transplante renal submetidos à hemodiálise. Rev Sul-Bras Odontol, Curitiba 2009 7(1):50-6.
39. Gonçalves ÉM, Karam LALL, Milfont TS, Araújo MD, Santana JML, Lima DLF. Prevalence of Periodontitis in Maintenance Hemodialysis Patients. J BrasNefrol 2007 set.;29(3):115-9.

40. Ardalan MR, Ghabili K, Pourabbas R, Shoja MM. A causative link between periodontal disease and glomerulonephritis: a preliminary study. Ther Clin Risk Manag 2011 7(93-8.

41. Kshirsagar AV, Moss KL, Elter JR, Beck JD, Offenbacher S, Falk RJ. Periodontal disease is associated with renal insufficiency in the Atherosclerosis Risk In Communities (ARIC) study. Am J Kidney Dis 2005 Apr;45(4):650-7.

42. Seraj B, Ahmadi R, Ramezani N, Mashayekhi A, Ahmadi M. Oro-dental health status and salivary characteristics in children with chronic renal failure. J Dent (Tehran) 2011 Summer;8(3):146-51.

43. Van Steenberghe D. Distúrbios sistêmicos e o periodonto. In: Lindhe J. Tratado de periodontia clínica e implantodontia oral. Rio de Janeiro: Guanabara Koogan; 1999. p. 233-49.

44. King GN, Healy CM, Glover MT, Kwan JT, Williams DM, Leigh IM, et al. Prevalence and risk factors associated with leukoplakia, hairy leukoplakia, erythematous candidiasis, and gingival hyperplasia in renal transplant recipients. Oral Surg Oral Med Oral Pathol 1994 Dec;78(6):718-26.

Recebido em 26/09/2014

Aceito em 11/03/2015 